\title{
Retraction: Evaluation of periimplant bone neoformation using different scanning electron microscope methods for measuring BIC. A dog study
}

\author{
José-Luis Calvo-Guirado ${ }^{1}$, Antonio Aguilar-Salvatierra ${ }^{2}$, Javier Guardia ${ }^{2}$, Rafael Delgado-Ruiz ${ }^{1}$, María-Piedad \\ Ramírez-Fernández ${ }^{1}$, Cristina Pérez-Sánchez ${ }^{3}$, Gerardo Gómez-Moreno ${ }^{2}$
}

\footnotetext{
${ }^{1}$ Department of Implant Dentistry, School of Medicine and Dentistry, University of Murcia, Spain

${ }^{2}$ Department of Pharmacological Interactions in Dentistry, Dental School, University of Granada, Spain

${ }^{3}$ Master of Implant Dentistry. Faculty of Medicine and Dentistry, University of Murcia
}

\section{Correspondence: \\ Mozart $N^{\circ} 1,1^{\circ} G$ \\ 30002. Murcia. Spain \\ joseluis.calvo@um.es}

Received: 29/06/2011 Accepted: $17 / 11 / 2011$

\begin{abstract}
Calvo-Guirado JL, Aguilar-Salvatierra A, Guardia J, Delgado-Ruiz R, Ramírez-Fernández MP, Pérez Sánchez C, Gómez-Moreno G. Retraction: Evaluation of periimplant bone neoformation using different scanning electron microscope methods for measuring BIC. A dog study. J Clin Exp Dent. 2019;11(5):e400-400.

http://www.medicinaoral.com/odo/volumenes/v11i5/jcedv11i5p400.pdf
\end{abstract}

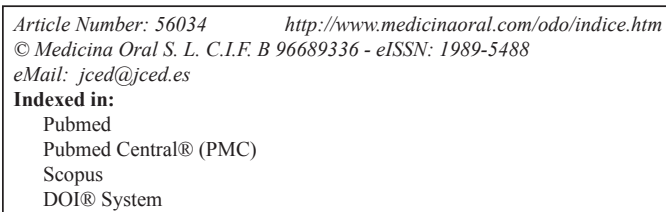

\begin{abstract}
In relation to the article of the Journal of Clinical and Experimental Dentistry "Calvo-Guirado JL, Aguilar-Salvatierra A, Guardia J, Delgado-Ruiz R, Ramírez-Fernández MP, Pérez-Sánchez C, Gómez-Moreno G. Evaluation of periimplant bone neoformation using different scanning electron microscope methods for measuring BIC. A dog study. J Clin Exp Dent. 2012 Feb 1;4(1):e8-e13", the authors have used three figures that are the same as those published in three different publications (J Pineal Res 2010; COIR 2010; COIR 2012). The copyright of the mentioned publications was consequently not respected. Retraction of the article is therefore decided.
\end{abstract}

